Vol. 2, No. 2, Desember 2017, pISSN 2527-2853, eISSN 2549-2985

\title{
Analisa Sinkretisme Agama dan Budaya Melalui Transformasi Elemen Visual Bernilai Sakral pada Gereja Katolik Ganjuran
}

\author{
Ira Audia Agustina ${ }^{1}$, Andryanto Wibisono ${ }^{2}$, Imam Santosa ${ }^{2}$ \\ ${ }^{1}$ Mahasiswa Magister Desain, Fakultas Seni Rupa dan Desain, Institut Teknologi Bandung \\ ${ }^{2}$ Dosen Magister Desain, Fakultas Seni Rupa dan Desain, Institut Teknologi Bandung \\ xminddesign@gmail.com
}

\begin{abstract}
ABSTRAK
Kebudayaan Jawa adalah kebudayaan yang terbentuk sebagai hasil perpaduan berbagai macam kultur agama dan budaya, dimana usaha manusia Jawa untuk memadukan nilai-nilai baru dan nilai lokal dapat dilihat jejaknya melalui berbagai karya seni visual sebagai hasil ekspresi simbolis-religiusnya. Melalui Gereja Ganjuran ini dapat dilihat adanya usaha untuk melakukan proses sinkretisme dengan memadukan nilai ajaran Katolik dengan nilai Hindu-Jawa melalui elemen-elemen visualnya sehingga bernilai sakral baik secara budaya maupun agama. Penelitian ini menganalisa mengenai proses sinkretisme tersebut melalui analisa elemen-elemen visualnya dengan menggunakan pendekatan kualititif estetika visual dan kebudayaan Jawa. Dengan mengetahui bagaimana proses sinkretisme tersebut ditransformasikan kedalam elemen visual yang diterima oleh masyarakat, diharapkan penelitian dapat menjadi landasan mengenai konsep dalam implementasi nilai-nilai kesakralan kedalam sebuah karya seni visual yang bermakna simbolis.
\end{abstract}

Kata kunci: sinkretisme; budaya; transformasi; elemen visual bernilai sacral; Gereja Katolik

\section{ABSTRACT}

Javaneseculture is formed from combinations of various kinds of religion and cultures, in which the Javanese's peoples effort to integrate the outside and local values can be seen in its footsteps through the various works of visual arts as their symbolic religious expression. Through this Ganjuran Church, the attempt to syncretism process of Catholic teachings and Hindu-Javanese values can be seen in its visual elements so that it valued by sacredness worth both culturally and religiously. This study analyzes the process through the visual elements analysis by using the qualitative approach of visual aesthetic and Javanese culture. By knowing the process of how syncretism is transformed into visual elements that is well-received by public, it is expected to get the basis concept of sacredness implementation into the symbolic visual artworks.

Keyword: syncretism; culture; transformation; sacred images; Catholic Church.

\section{PENDAHULUAN}

Dalam sejarah perkembangan kebudayaan di Indonesia terutama Jawa, dapat dilihat bahwa proses sinkretisme inilah yang membentuk budaya Jawa hingga saat ini. Hal ini dapat dilihat melalui sejarah masuknya agama Hindu yang dibawa oleh pedagang dari India pada abad ke 6, lantas diikuti oleh masuknya agama Buddha pada abad ke VIII dimana pada abad inilah dinasti Syailendra berkuasa dan mendirikan stupa Buddha terbesar di dunia yaitu Candi Borobudur. Setelah itu, pada abad ke IX tercatat keberadaan kerajaan Demak yang beragama Islam meskipun tidak berumur panjang (Magnis-Suseno, 2003). Agama Katolik termasuk yang datang belakangan, dimana tercatat pendirian stasi awal terdapat di Yogyakarta pada tahun 1864. Dalam proses masuknya agama-agama tersebut sehingga dapat diterima oleh masyarakatnya, terjadi sebuah sinkretisme, yaitu sebuah penyatuan dari beberapa kepercayaan yang cenderung berbeda, melalui kesamaan analogi dalam nilai dan mitos - mitos keagamaan, sehingga membentuk sebuah inklusifitas terhadap agama-agama lain. 
Ira Audia Agustina, Andryanto Wibisono, Imam Santosa

Analisa Sinkretisme Agama dan Budaya Melalui Transformasi Elemen Visual Bernilai Sakral pada Gereja

Katolik Ganjuran

Sinkretisme sendiri berasal dari Bahasa Yunani "Sunkretamos" yang mempunyai arti "kesatuan", yang dicetuskan oleh Plutarch (46-120 M) yang lebih mengarah ke pengertian politik. Gereja Katolik memahami pentingnya sebuah agama untuk bersedia menyatukan diri dalam cara pandang kebudayaan lokal, dimana hal inipun telah tercantum dalam aturan Sacrosanctum Concillium no 37-40. Berdasarkan pemahaman tersebut, maka Gereja Katolik berusaha memasukkan nilai-nilai kebudayaan dalam setiap elemen visual bernilai sakral yang terdapat dalam setiap bangunan ibadah Gereja Katolik.

Elemen visual bernilai sakral ini sendiri bagi Gereja Katolik adalah sebuah simbolisasi bentuk-bentuk simbolik 'realitas surgawi' kedalam 'realitas duniawi' (Srisadono, 2012). Dalam sejarahnya, elemen visual bernilai sakral agama Katolik adalah sebuah artifak kebudayaan fisik yang lahir dan berkembang di Eropa, dipengaruhi oleh alam pandang dan budaya kesenian zaman Romawi, dimana pada masa itu elemen visual ikut berperan penting dalam perkembangan kesenirupaan Barat. Oleh karena itu, meskipun agama Katolik telah menyebar ke hampir berbagai penjuru dunia termasuk di Jawa, penggunaan elemen visual bernilai sakral sebagian besar masih tetap berkiblat kedalam bentuk kesenian Barat yang cenderung ' $k i t s c h$ ' atau hasil produksi massal berkualitas rendah (Schmutzer dalam Laksana, 2011).

Dalam penciptaan sebuah karya seni visual, konsep estetika Barat memiliki perbedaan yang amat bertolak belakang dengan konsep estetika Asia, terutama Asia Tenggara. Konsep estetika visual Barat merupakan hasil dari cara berpikir rasional yang runut, sistematis, transparan, logis, dan matematis. Proses cara berpikir tersebut dipelopori oleh para filsuf Yunani melalui Sokrates, Plato, Aristoteles, dan Archimedes. Oleh karena itu, hasil karya visual Barat lebih berkesan realistis, dramatis, dan bertumpu pada pemahaman estetika keindahan sebagai pemuas rasa (Mangunwijaya, 1988; Widagdo, 2011). Sementara konsep estetika visual pada kebudayaan Jawa adalah estetika sebagai simbolisasi kosmologis, dimana kata 'seni' tidak dikenal dalam kerangka budaya, melainkan merupakan sesuatu yang memiliki arti luas, sangat terikat, dan menyatu dengan kehidupan manusia secara keseluruhan, sehingga berolah seni adalah suatu bentuk ekspresi spiritual (Widagdo, 2011). Oleh karena itu, konsep estetika Jawa tidak mengenal konsep 'keindahan' seperti dalam estetika Barat yang berada dalam kerangka segi kenikmatan indrawi. Estetika kebudayaan Jawa berada pada tahap primer dimana orang berpikir atau bercita-rasa dalam alam penghayatan kosmis dan mitis, atau agama. Segi mitos atau keagamaan tersebut menyangkut ke-'Ada'an manusia atau semesta dari dasar-dasarnya yan paling akar, paling menentukan, paling sejati, dimana dalam alam pikiran mitis, manusia masih menghayati diri tenggelam di dan bersama seluruh alam dan dunia gaib (Mangunwijaya, 1988).

\section{METODE PENELITIAN}

Berdasarkan latar belakang tersebut, penelitian ini melandaskan pada proses sinkretisme melalui transformasi elemen-visual bernilai sakral pada sebuah Gereja Katolik, yang dianalisa melalui pemaknaan unsur-unsur visualnya melalui pendekatan kebudayaan dan estetika visual. Persoalan yang menarik adalah bagaimana sebuah nilai Kekatolikan yang berasal dari budaya Timur Tengah dan berkembang di Barat dapat disematkan kedalam unsur visual Hindu-Jawa yang memiliki nilai kesakralan kosmologis didalamnya, dan bagaimana hal tersebut dapat dipahami oleh umat Katolik-Jawa maupun masyarakat Jawa secara umumnya tanpa menimbulkan penolakan di dalam prosesnya. 


\section{HASIL PENELITIAN DAN PEMBAHASAN}

Gereja Ganjuran didirikan pada tahun 1927 oleh Joseph Schmutzer yang berprofesi sebagai pengusaha perkebunan tebu sekaligus sebagai misionaris. Gereja ini sendiri terletak di Bantul, $17 \mathrm{~km}$ Selatan Yogyakarta. Meskipun mengalami perombakan total pada bangunan ibadahnya akibat terkena gempa pada tahun 2006, namun elemen-elemen visual bernilai sakral pada gereja ini hampir tidak mengalami perubahan sama sekali. Hal yang menarik pada Gereja Ganjuran ini adalah jangkauan karakteristik peziarah yang tidak hanya berasal dari kalangan umat Katolik saja, melainkan juga terdapat banyak peziarah dari berbagai aliran kepercayaan lainnya.

Schmutzer memang menciptakan konsep elemen visual bernilai sakral pada Gereja Ganjuran dengan konsep eklektis menggunakan perpaduan unsur-unsur visual Hindu-Jawa dalam menggambarkan ideologi Kekrisenan. Bagi Schmutzer, karya seni Hindu-Jawa menggambarkan keelokkan kualitas dan keindahan dalam penyampaian makna keabadian di dalamnya (Laksana, 2011). Dalam proses penciptaannya, Schmutzer menghilangkan symbolsimbol Hinduisme dan hanya mengambil bentukan artistiknya, sehingga diharapkan "...bentukan artistik tersebut dengan sendirinya akan menyatu kedalam ideologi Kekristenan" (Laksana, 2011). Oleh Schmutzer, hal ini menjadi suatu prinsip utama pemisahan antara bentukan-bentukan artistik dengan konsep religiusitas Hindu-Jawa.

Terdapat beberapa elemen visual bernilai sakral yang tersebar pada seluruh area Gereja Ganjuran, namun dalam jurnal ini, obyek penelitian akan ditekankan pada Tabernakel dan Arca Bunda Maria yang terdapat pada bangunan ibadah umum Gereja Ganjuran. Kedua obyek tersebut dipilih karena dianggap dapat mewakili transformasi elemen visual sebagai hasil sinkretisme antara agama lokal dan Kekristenan.

\section{A. Tabernakel}

Awal mula keberadaan Tabernakel ini berasal dari sejarah bangsa Yahudi mengenai sebuah benda sakral bernama Tabut Perjanjian, yaitu sebuah kotak emas yang berisikan dua loh batu bertuliskan Sepuluh Perintah Allah. Sedangkan Tabernakel dalam fungsinya saat ini adalah sebagai perlambang kehadiran Tuhan di tengah-tengah umatNya. Dalam konteks teologis, Tabernakel merupakan perlambangan kehadiran Tuhan dalam setiap perayaan ibadah umat Katolik (Ekaristi). Tabernakel Gereja Ganjuran yang dihiasi oleh arca seraphim/malaikat mempertegas fokus tabernakel sebagai simbolisasi Tahta Allah. Keberadaan malaikat dalam Katolik adalah sebagai salah satu makhluk ciptaan Tuhan yang mengabdi secara langsung kepada Tuhan; sebagai perantara komunikasi antara Tuhan dan manusia; sebagai salah satu makhluk yang ditugaskan untuk menolong dan menjaga umatNya; dan sebagai prajurit dalam peperangan melawan Iblis. Sementara, dalam kepercayaan Hindu-Jawa tidak terdapat malaikat. Sebaliknya, para Dewa dalam kepercayaan Hindu mempunyai derajat yang dianggap sama dengan malaikat. Dalam Hindu, para Dewa hanyalah perantara Tuhan dan memiliki manifestasi kekuatan Tuhan dalam jumlah yang kecil saja (Bhagavad Gita, 7:22). 
Ira Audia Agustina, Andryanto Wibisono, Imam Santosa

Analisa Sinkretisme Agama dan Budaya Melalui Transformasi Elemen Visual Bernilai Sakral pada Gereja

Katolik Ganjuran

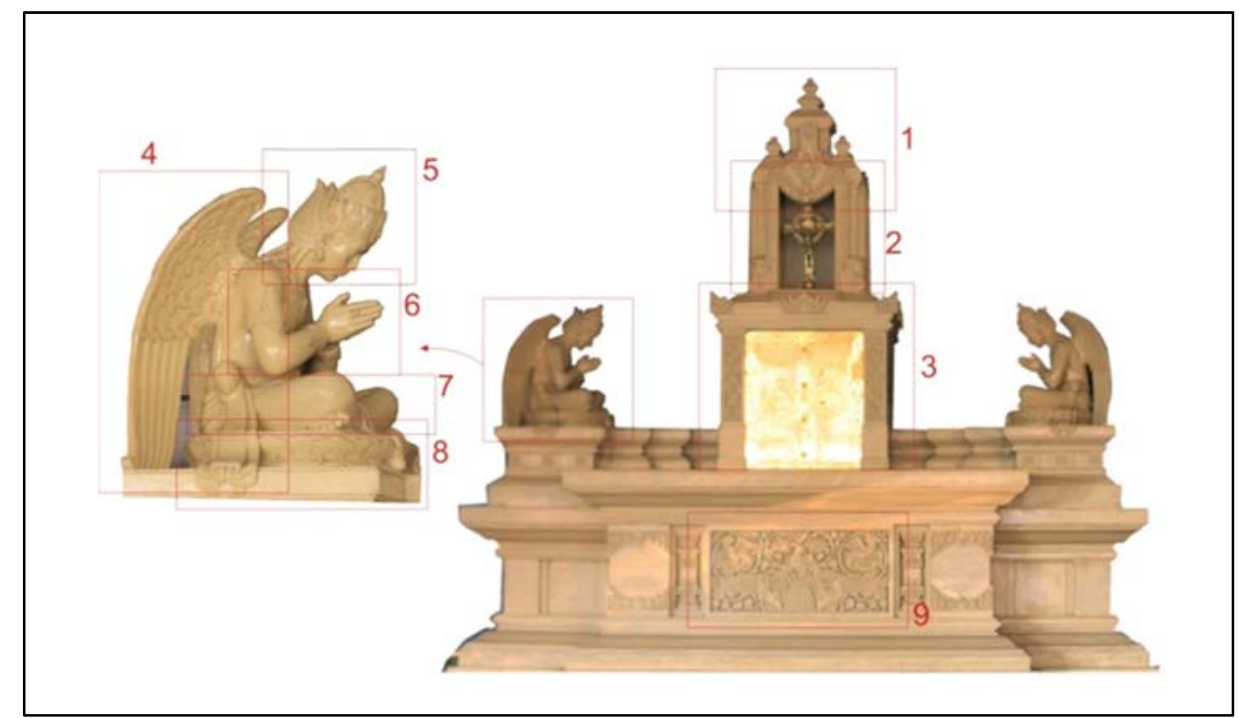

Gambar 1. Pembagian unsur-unsur visual yang akan dianalisa pada tabernakel Sumber: konstruksi pribadi (2017)

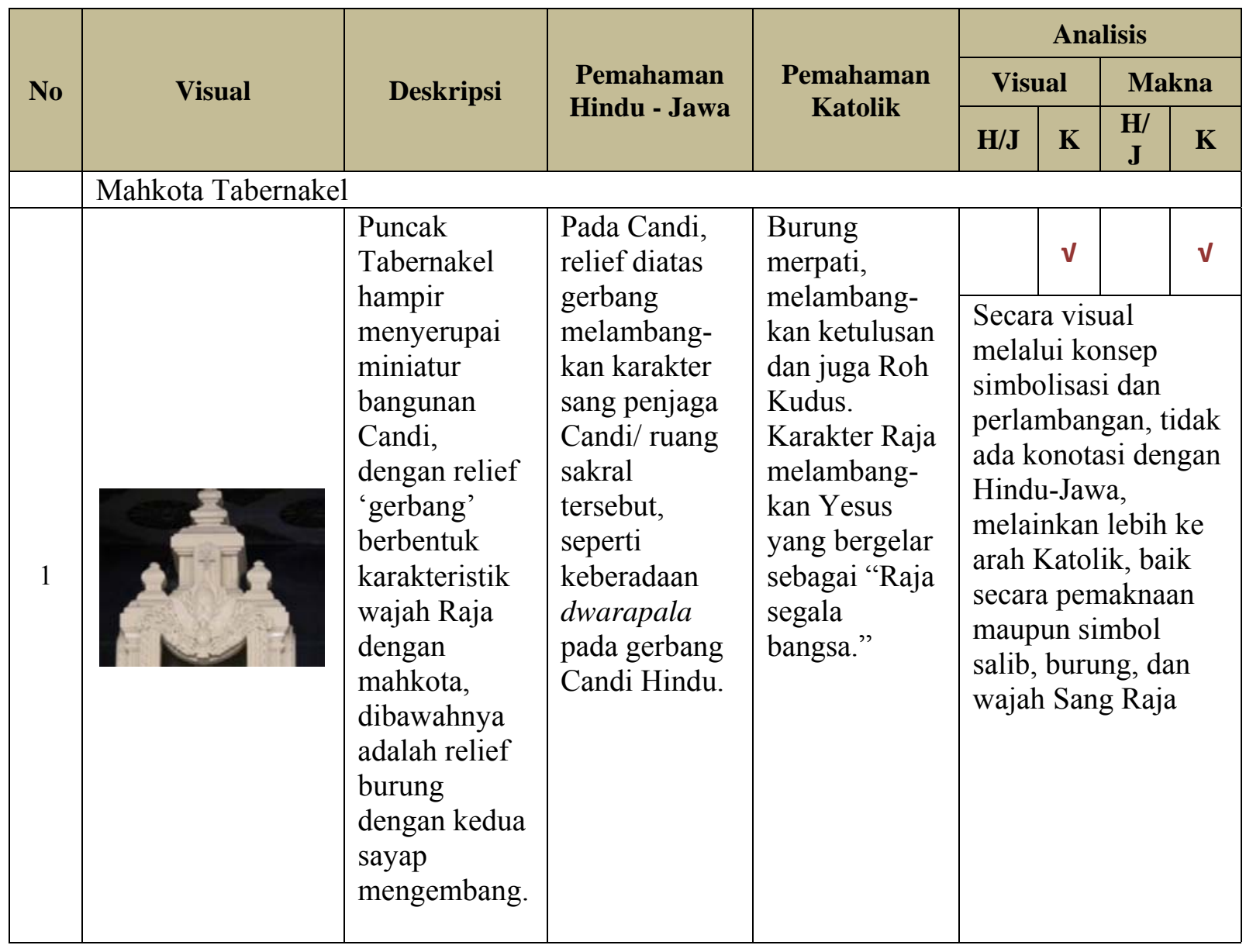




\begin{tabular}{|c|c|c|c|c|c|c|c|c|}
\hline \multirow{3}{*}{ No } & \multirow{3}{*}{ Visual } & \multirow{3}{*}{ Deskripsi } & \multirow{3}{*}{$\begin{array}{c}\text { Pemahaman } \\
\text { Hindu - Jawa }\end{array}$} & \multirow{3}{*}{$\begin{array}{c}\text { Pemahaman } \\
\text { Katolik }\end{array}$} & \multicolumn{4}{|c|}{ Analisis } \\
\hline & & & & & \multicolumn{2}{|c|}{ Visual } & \multicolumn{2}{|c|}{ Makna } \\
\hline & & & & & $\mathbf{H} / \mathbf{J}$ & $\mathbf{K}$ & $\begin{array}{c}\mathbf{H} / \\
\mathbf{J}\end{array}$ & $\mathbf{K}$ \\
\hline \multirow[b]{2}{*}{2} & & \multirow[b]{2}{*}{$\begin{array}{l}\text { Rongga } \\
\text { ditengah- } \\
\text { tengah } \\
\text { mahkota yang } \\
\text { diisi dengan } \\
\text { ornamen } \\
\text { logam } \\
\text { berbentuk } \\
\text { salib dengan } \\
\text { corpus } \\
\text { ditengahnya. }\end{array}$} & \multirow{2}{*}{$\begin{array}{l}\text { Rongga ini } \\
\text { bisa } \\
\text { diidentikkan } \\
\text { dengan } \\
\text { grabagriha, } \\
\text { yaitu ruangan } \\
\text { pusat Candi } \\
\text { tempat } \\
\text { diletakkannya } \\
\text { Arca utama. }\end{array}$} & \multirow{2}{*}{$\begin{array}{l}\text { Salib } \\
\text { merupakan } \\
\text { inti dari ajaran } \\
\text { Katolik, yang } \\
\text { berfokus pada } \\
\text { pemahaman } \\
\text { akan konsep } \\
\text { penebusan } \\
\text { Yesus di kayu } \\
\text { Salib. }\end{array}$} & & 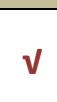 & & v \\
\hline & & & & & \multicolumn{4}{|c|}{$\begin{array}{l}\text { Tidak ada konotasi } \\
\text { dengan Hindu-Jawa } \\
\text { sama sekali, karena } \\
\text { Corpus telah } \\
\text { menjadi identifikasi } \\
\text { ajaran Katolik. }\end{array}$} \\
\hline \multirow[b]{2}{*}{3} & & \multirow{2}{*}{$\begin{array}{l}\text { Pintu lemari } \\
\text { yang terbuat } \\
\text { dari plakat } \\
\text { kuningan } \\
\text { dengan } \\
\text { ornamen } \\
\text { geometris dan } \\
\text { simbol " } \alpha " \\
\text { (alpha) dan } \\
\text { " } \Omega \text { " (omega) }\end{array}$} & \multirow[t]{2}{*}{$\begin{array}{l}\text { Tidak ada } \\
\text { konsep. }\end{array}$} & \multirow{2}{*}{$\begin{array}{l}\text { Simbol " } \alpha " \\
\text { mempunyai } \\
\text { arti "awal", } \\
\text { dan simbol } \\
\text { " } \Omega \text { " mempu- } \\
\text { nyai arti akhir } \\
\text { dalam bahasa } \\
\text { Yunani. Sim- } \\
\text { bolisasi ini } \\
\text { juga terdapat } \\
\text { dalam literatur } \\
\text { Alkitab ( } \\
\text { Wahyu 21:5) }\end{array}$} & & $\checkmark$ & & v \\
\hline & & & & & \multicolumn{4}{|c|}{$\begin{array}{l}\text { Tidak ada konotasi } \\
\text { dengan Hindu-Jawa } \\
\text { sama sekali, karena } \\
\text { lambang Yunani ini } \\
\text { menjadi salah satu } \\
\text { identifikasi ajaran } \\
\text { Katolik. }\end{array}$} \\
\hline & \multicolumn{8}{|c|}{ Arca Seraphim } \\
\hline \multirow[b]{2}{*}{4} & & $\begin{array}{l}\text { Sayap yang } \\
\text { menyerupai }\end{array}$ & $\begin{array}{l}\text { Dalam Hindu } \\
\text { karakter ber- }\end{array}$ & $\begin{array}{l}\text { Sayap adalah } \\
\text { lambang }\end{array}$ & & $\sqrt{ }$ & & $\sqrt{ }$ \\
\hline & & $\begin{array}{l}\text { arca malaikat } \\
\text { Gereja } \\
\text { Ganjuran, } \\
\text { dalam posisi } \\
\text { yang terlipat } \\
\text { di punggung. }\end{array}$ & $\begin{array}{l}\text { dimiliki oleh } \\
\text { makhluk an- } \\
\text { thropomorph } \\
\text { manusia ber- } \\
\text { kepala bu- } \\
\text { rung, Garuda, } \\
\text { dan juga bu- } \\
\text { rung-burung } \\
\text { mitos dalam } \\
\text { Jawa seperti } \\
\text { burung } \\
\text { prenjak }\end{array}$ & $\begin{array}{l}\text { dan juga } \\
\text { lambang } \\
\text { penghubung } \\
\text { antara dunia } \\
\text { bawah (bumi) } \\
\text { dan dunia atas } \\
\text { (langit). }\end{array}$ & \multicolumn{4}{|c|}{$\begin{array}{l}\text { Tidak ada konotasi } \\
\text { dengan Hindu-Jawa } \\
\text { sama sekali. }\end{array}$} \\
\hline
\end{tabular}


Ira Audia Agustina, Andryanto Wibisono, Imam Santosa

Analisa Sinkretisme Agama dan Budaya Melalui Transformasi Elemen Visual Bernilai Sakral pada Gereja

Katolik Ganjuran

\begin{tabular}{|c|c|c|c|c|c|c|c|c|}
\hline \multirow{3}{*}{ No } & \multirow{3}{*}{ Visual } & \multirow{3}{*}{ Deskripsi } & \multirow{3}{*}{$\begin{array}{l}\text { Pemahaman } \\
\text { Hindu - Jawa }\end{array}$} & \multirow{3}{*}{$\begin{array}{l}\text { Pemahaman } \\
\text { Katolik }\end{array}$} & \multicolumn{4}{|c|}{ Analisis } \\
\hline & & & & & \multicolumn{2}{|c|}{ Visual } & \multicolumn{2}{|c|}{ Makna } \\
\hline & & & & & H/J & K & H/J & K \\
\hline & & & $\begin{array}{l}\text { Sebagai tanda } \\
\text { kemakmuran } \\
\text { atau burung } \\
\text { gagak atau } \\
\text { srinthil } \\
\text { sebagai } \\
\text { pertanda akan } \\
\text { adanya } \\
\text { kematian. }\end{array}$ & & & & & \\
\hline \multirow[b]{2}{*}{5} & & \multirow[b]{2}{*}{$\begin{array}{l}\text { Kepala } \\
\text { menunduk } \\
\text { yang melam- } \\
\text { bangkan eks- } \\
\text { presi khidmat } \\
\text { dan penghor- } \\
\text { matan, de- } \\
\text { ngan karakter } \\
\text { wajah ma- } \\
\text { nusia lengkap } \\
\text { dengan mah- } \\
\text { kota kepala } \\
\text { yang dihiasi } \\
\text { ornamen }\end{array}$} & \multirow{2}{*}{$\begin{array}{l}\text { Dalam Candi- } \\
\text { Candi Hindu, } \\
\text { karakteristik } \\
\text { manusia } \\
\text { dengan } \\
\text { mahkota } \\
\text { kepala sering } \\
\text { diidentikkan } \\
\text { dengan } \\
\text { seorang dewa. }\end{array}$} & \multirow[b]{2}{*}{$\begin{array}{l}\text { Bentukan } \\
\text { malaikat pada } \\
\text { Katolik- } \\
\text { Barat: berke- } \\
\text { pala manusia } \\
\text { dengan wajah } \\
\text { rupawan/ } \\
\text { sempurna, } \\
\text { tanpa } \\
\text { mahkota, } \\
\text { lebih } \\
\text { mengandung } \\
\text { unsur estetika. }\end{array}$} & & $v$ & & $\boldsymbol{v}$ \\
\hline & & & & & \multicolumn{4}{|c|}{$\begin{array}{l}\text { Secara visual tidak } \\
\text { ada konotasi dengan } \\
\text { Katolik, melainkan } \\
\text { lebih dikenal } \\
\text { sebagai karakter } \\
\text { pada penokohan } \\
\text { Dewa/ pewayangan } \\
\text { budaya Hindu-Jawa. }\end{array}$} \\
\hline \multirow[b]{2}{*}{6} & & \multirow[b]{2}{*}{$\begin{array}{l}\text { Gestur kedua } \\
\text { tangan saling } \\
\text { menangkup di } \\
\text { depan dada, } \\
\text { dengan posisi } \\
\text { punggung } \\
\text { sedikit } \\
\text { membungkuk. } \\
\text { Pada kedua } \\
\text { tangan } \\
\text { nampak } \\
\text { hiasan gelang }\end{array}$} & \multirow[b]{2}{*}{$\begin{array}{l}\text { Gestur ini } \\
\text { adalah wujud } \\
\text { "sungkem": } \\
\text { penghormatan } \\
\text { seorang abdi } \\
\text { dalem saat } \\
\text { menghadap } \\
\text { seorang Raja, } \\
\text { yg hingga kini } \\
\text { masih } \\
\text { dipraktekkan } \\
\text { dalam } \\
\text { lingkungan } \\
\text { keraton. }\end{array}$} & \multirow[b]{2}{*}{$\begin{array}{l}\text { Tidak ada } \\
\text { konsep, lebih } \\
\text { cenderung } \\
\text { bebas dengan } \\
\text { kedua tangan } \\
\text { terentang di } \\
\text { samping } \\
\text { badan } \\
\text { melambang- } \\
\text { kan peneri- } \\
\text { maan, atau } \\
\text { sambil } \\
\text { membawa } \\
\text { terompet/ } \\
\text { pedang. }\end{array}$} & & $v$ & & $\mathbf{v}$ \\
\hline & & & & & \multicolumn{4}{|c|}{$\begin{array}{l}\text { Secara visual } \\
\text { maupun pemaknaan, } \\
\text { lebih berkonotasi } \\
\text { Jawa. Pada Hindu } \\
\text { tidak terdapat gestur } \\
\text { ini. Menjadi sumber } \\
\text { konsepsi } \\
\text { 'penghormatan' } \\
\text { dalam sudut } \\
\text { pandang Katolik. }\end{array}$} \\
\hline
\end{tabular}




\begin{tabular}{|c|c|c|c|c|c|c|c|c|}
\hline \multirow{3}{*}{ No } & \multirow{3}{*}{ Visual } & \multirow{3}{*}{ Deskripsi } & \multirow{3}{*}{$\begin{array}{c}\text { Pemahaman } \\
\text { Hindu - Jawa }\end{array}$} & \multirow{3}{*}{$\begin{array}{c}\text { Pemahaman } \\
\text { Katolik }\end{array}$} & \multicolumn{4}{|c|}{ Analisis } \\
\hline & & & & & \multicolumn{2}{|c|}{ Visual } & \multicolumn{2}{|c|}{ Makna } \\
\hline & & & & & $\mathbf{H} / \mathbf{J}$ & $\mathbf{K}$ & $\mathbf{H} / \mathbf{J}$ & $\mathbf{K}$ \\
\hline \multirow[b]{2}{*}{7} & & \multirow{2}{*}{$\begin{array}{l}\text { Posisi duduk } \\
\text { adalah bersila, } \\
\text { seperti orang } \\
\text { yang sedang } \\
\text { bersemedi. }\end{array}$} & \multirow[b]{2}{*}{$\begin{array}{l}\text { Posisi bersila } \\
\text { adalah posisi } \\
\text { meditasi yang } \\
\text { hingga kini } \\
\text { masih diprak- } \\
\text { tekkan dalam } \\
\text { berbagai keper- } \\
\text { cayaan yang } \\
\text { berasal dari } \\
\text { daratan Asia. }\end{array}$} & \multirow{2}{*}{$\begin{array}{l}\text { Patung } \\
\text { malaikat gaya } \\
\text { Eropa rata-rata } \\
\text { dengan posisi } \\
\text { berdiri, atau } \\
\text { berlutut. Tidak } \\
\text { mengenal } \\
\text { konsep duduk } \\
\text { bersila. }\end{array}$} & $\boldsymbol{v}$ & & v & \\
\hline & & & & & \multicolumn{4}{|c|}{$\begin{array}{l}\text { Secara visual maupun } \\
\text { makna, mengambil } \\
\text { konsep 'bersila' atau } \\
\text { posisi semedi. } \\
\text { Melambangkan sikap } \\
\text { duduk seseorang } \\
\text { dengan tingkat } \\
\text { rohaniah yang tinggi } \\
\text { dalam budaya Jawa. }\end{array}$} \\
\hline \multirow[b]{2}{*}{8} & & \multirow{2}{*}{$\begin{array}{l}\text { Landasan } \\
\text { duduk bundar } \\
\text { dengan hiasan } \\
\text { kelopak bunga } \\
\text { padma/ teratai }\end{array}$} & \multirow{2}{*}{$\begin{array}{l}\text { Bunga padma } \\
\text { dalam } \\
\text { kepercayaan } \\
\text { Hindu-Buddha } \\
\text { melambangkan } \\
\text { kesucian orang } \\
\text { yang duduk } \\
\text { diatasnya. }\end{array}$} & \multirow[b]{2}{*}{$\begin{array}{l}\text { Tidak ada } \\
\text { konsep. Namun } \\
\text { Padmasana ini } \\
\text { dimaksudkan } \\
\text { sebagai } \\
\text { pengganti } \\
\text { lingkaran } \\
\text { kesucian/halo } \\
\text { yang biasa } \\
\text { digunakan } \\
\text { sebagai } \\
\text { perlambang } \\
\text { orang-orang } \\
\text { suci. }\end{array}$} & $\boldsymbol{v}$ & & v & \\
\hline & & & & & \multicolumn{4}{|c|}{$\begin{array}{l}\text { Secara visual maupun } \\
\text { makna, } \\
\text { melambangkan } \\
\text { konsepsi 'kesucian' } \\
\text { dalam kebudayaan } \\
\text { Hindu/ Buddha. }\end{array}$} \\
\hline \multirow[b]{2}{*}{9} & & \multirow[b]{2}{*}{$\begin{array}{l}\text { Ornamen } \\
\text { tanaman, } \\
\text { bunga, burung, } \\
\text { dan makhluk } \\
\text { hidup lainnya } \\
\text { dengan tema } \\
\text { yang } \\
\text { menampilkan } \\
\text { keragaman } \\
\text { hutan. }\end{array}$} & \multirow{2}{*}{$\begin{array}{l}\text { Ornamen stilasi } \\
\text { khas tanah } \\
\text { Jawa yg } \\
\text { menjadi } \\
\text { perlambang } \\
\text { kesuburan dan } \\
\text { keindahan } \\
\text { hayati alam } \\
\text { Jawa. }\end{array}$} & \multirow[b]{2}{*}{$\begin{array}{l}\text { Stilasi } \\
\text { tumbuhan pada } \\
\text { karya seni } \\
\text { Eropa biasanya } \\
\text { dipengaruhi } \\
\text { oleh gaya Art } \\
\text { Nouveau. } \\
\text { Lebih } \\
\text { mengarah } \\
\text { kepada estetika } \\
\text { dibanding } \\
\text { makna. }\end{array}$} & $\boldsymbol{v}$ & & & $\mathbf{v}$ \\
\hline & $\cdots$ & & & & \multicolumn{4}{|c|}{$\begin{array}{l}\text { Secara pemaknaan } \\
\text { tidak berkonotasi pada } \\
\text { Katolik atau Hindu- } \\
\text { Jawa. Secara visual, } \\
\text { relief pahatan nampak } \\
\text { jelas bercorak Jawa. }\end{array}$} \\
\hline
\end{tabular}

Tabernakel Gereja Ganjuran yang berfungsi sebagai manifestasi keberadaan Tuhan lebih menitik beratkan pada sudut pandang kepercayaan Hindu-Jawa secara visual, namun saat dilihat secara menyeluruh terdapat unsur-unsur visual Katolik yang cukup mencolok dan hal ini mampu merubah pemaknaan arca malaikat tersebut untuk masuk sepenuhnya kedalam pemaknaan nilai Katolik. Unsur- unsur visual tersebut adalah:

1. Detail relief dan penempatan corpus pada bagian mahkota dan rongga Tabernakel (garbagriha) menjadi simbol utama yang menciptakan penghubung kepada nilai Kekatolikan. 
Ira Audia Agustina, Andryanto Wibisono, Imam Santosa

Analisa Sinkretisme Agama dan Budaya Melalui Transformasi Elemen Visual Bernilai Sakral pada Gereja

Katolik Ganjuran

2. Ornamen pada pintu logam lemari penyimpanan dengan lambang khusus Kristiani, yaitu ' $\alpha$ '(Alpha) dan ' $\Omega$ ' (Omega).

3. Keberadaan sayap pada arca malaikat.

4. Posisi kedua malaikat yang mengapit tabernakel, secara langsung akan menghubungkan umat dengan mitos keberadaan Tabut Perjanjian.

Arca malaikat yang secara visual meminjam bentukan dewa Hinduisme, akan menimbulkan kontradiksi apabila masih tetap menggunakan pemahaman Hindu-Jawa, karena tidak mungkin bagi seorang Dewa digambarkan menunduk dan menyembah, karena posisi mereka sendiri sudah cukup tinggi. Namun berdasarkan pemahaman mengenai posisi Dewa dalam Hinduisme adalah seorang perantara bagi Tuhan terhadap manusia itu sendiri. Kemiripan konsep dasar keberadaan dewa ini menimbulkan pemahaman akan karakter seorang malaikat yang diberi kemampuan dan kekuatan selayaknya dewa-dewa dalam kepercayaan Hinduisme, namun tetaplah mereka hanya seorang abdi (hamba) yang bertugas untuk melayani perintah Tuan (Tuhan)-nya.

Pemahaman akan gestur dan makna tersebut mengingatkan umat akan sikap yang tulus dan khidmat dalam penyembahan, dan sebagai penggambaran kebudayaan masyarakat Jawa yang religius dimana tindakan 'sungkem' adalah suatu bentuk penghormatan yang mendalam, dan bukan suatu bentuk ketakutan terhadap suatu bentuk kekuasaan. Hal ini juga menggambarkan sikap hidup masyarakat Jawa yang selalu menerima posisi dan keberadaan dirinya di kehidupan sebagai sesuatu yang sudah ditentukan oleh Tuhan.Karakter malaikat tersebut juga dapat disematkan sebagai seorang manusia Jawa yang berpandangan sosio-religius, dimana pemusatan diri terhadap nilai-nilai religius atau unsur Ketuhananan menjadi satu motivasi dasar dan bagian tak terpisahkan dalamsetiap aktifitas yang dilakukan oleh manusia Jawa.

\section{B. Arca Bunda Maria}

Arca Bunda Maria pada Gereja Ganjuran dibentuk berdasarkan model Arca Prajnaparamitha yang saat ini terdapat pada Museum Nasional Jakarta. Prajnaparamitha sendiri adalah gelar yang disematkan pada seorang Buddhist wanita yang melambang suatu kebijaksanaan transedental yang sempurna dalam aliran Buddha Mahayana. Penggambaran secara visual Arca Bunda Maria Ganjuran nampak lebih mengarah kedalam model estetik Hindu-Jawa, dengan unsur estetika Barat dan modernisasi yang nampak pada model serta detail ornamen pada pakaiannya yang tertutup penuh pada bagian dada, serta karakteristik wajahnya. Pemahaman akan penafsiran Arca sebagai karakteristik seorang Bunda Maria dalam ajaran Katolik dan bukan seorang Buddhist nampak dalam keberadaan anak kecil dalam pangkuan dan penyematan gelar yang terdapat dibawah Arca tersebut. 


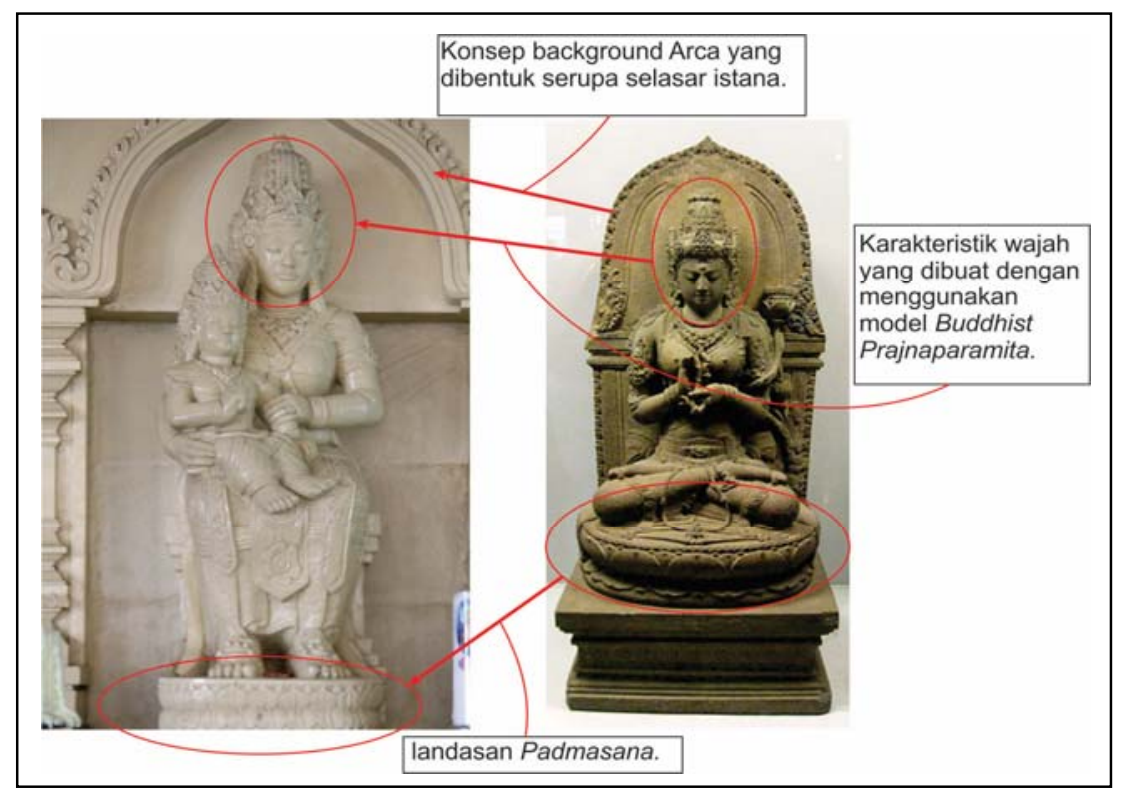

Gambar 2. Perbandingan Prajnaparamita dengan Arca Bunda Maria Sumber: konstruksi pribadi (2017)

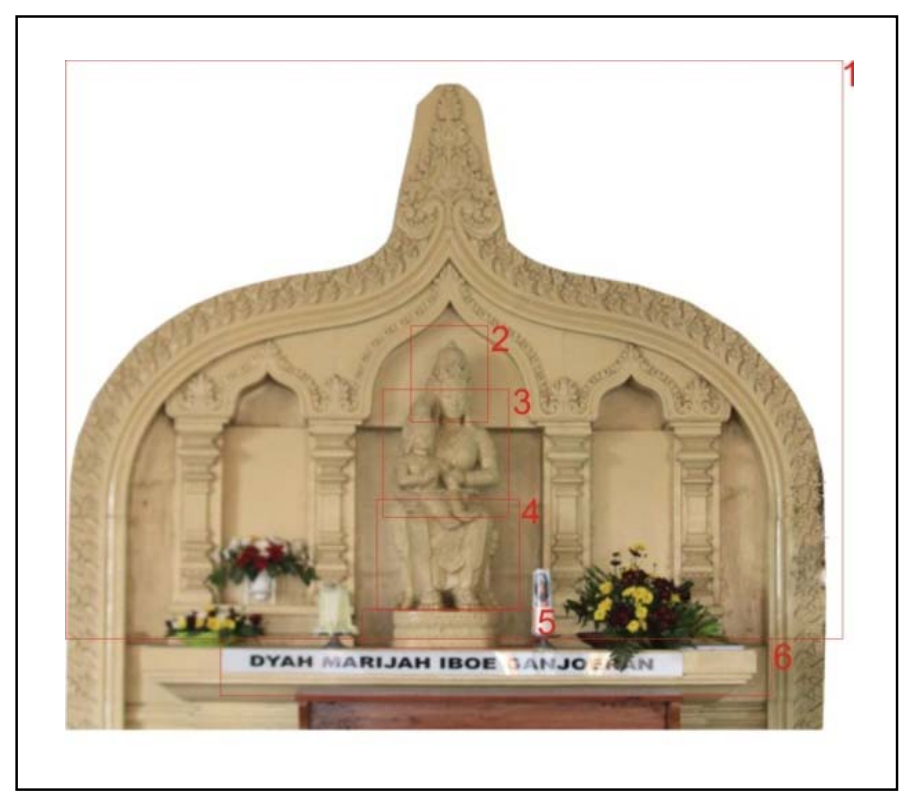

Gambar 3. Area unsur-unsur visual yang akan dianalisa pada Arca Bunda Maria Sumber: konstruksi pribadi (2017) 
Ira Audia Agustina, Andryanto Wibisono, Imam Santosa

Analisa Sinkretisme Agama dan Budaya Melalui Transformasi Elemen Visual Bernilai Sakral pada Gereja

Katolik Ganjuran

\begin{tabular}{|c|c|c|c|c|c|c|c|}
\hline \multirow{3}{*}{ Visual } & \multirow{3}{*}{ Deskripsi } & \multirow{3}{*}{$\begin{array}{c}\text { Pemahaman } \\
\text { Hindu - } \\
\text { Buddha }\end{array}$} & \multirow{3}{*}{$\begin{array}{l}\text { Pemahaman } \\
\text { KaTOLIK }\end{array}$} & \multicolumn{4}{|c|}{ Analisis } \\
\hline & & & & \multicolumn{2}{|c|}{ Visual } & \multicolumn{2}{|c|}{ Makna } \\
\hline & & & & H/B & $\mathbf{K}$ & H/B & K \\
\hline & $\begin{array}{l}\text { Background } \\
\text { Arca yang }\end{array}$ & $\begin{array}{l}\text { Melambangkan } \\
\text { sosok seorang }\end{array}$ & $\begin{array}{l}\text { Tidak ada } \\
\text { konsep. Namun }\end{array}$ & v & & & $\boldsymbol{V}$ \\
\hline & $\begin{array}{l}\text { menyerupai } \\
\text { selasar istana, } \\
\text { lengkap dengan } \\
\text { kolom dan } \\
\text { lorong. }\end{array}$ & $\begin{array}{l}\text { Ratu yang } \\
\text { memiliki kuasa } \\
\text { di dalam Istana }\end{array}$ & $\begin{array}{l}\text { menciptakan } \\
\text { pemahaman } \\
\text { bahwa sang } \\
\text { wanita juga } \\
\text { memiliki kuasa } \\
\text { yang besar atas } \\
\text { sebuah } \\
\text { bangunan. }\end{array}$ & \multicolumn{4}{|c|}{$\begin{array}{l}\text { Secara visual } \\
\text { merujuk pada gaya } \\
\text { Hindu-Buddha, } \\
\text { sedangkan } \\
\text { pemaknaannya } \\
\text { cenderung netral, } \\
\text { tidak mengarah } \\
\text { pada Hindu-Jawa } \\
\text { ataupun Katolik. }\end{array}$} \\
\hline & \multirow{2}{*}{$\begin{array}{l}\text { Wajah tegak ke } \\
\text { depan dengan } \\
\text { kelopak mata } \\
\text { setengah } \\
\text { tertutup, ekspresi } \\
\text { tenang. } \\
\text { Menggunakan } \\
\text { mahkota di atas } \\
\text { kepala. }\end{array}$} & \multirow[b]{2}{*}{$\begin{array}{l}\text { Kelopak mata } \\
\text { setengah } \\
\text { tertutup } \\
\text { melambangkan } \\
\text { posisi meditatif } \\
\text { dan } \\
\text { ketenangan. } \\
\text { Mahkota } \\
\text { melambangkan } \\
\text { kekuasaan } \\
\text { yang dimiliki } \\
\text { oleh si wanita. } \\
\text { Dibat serupa } \\
\text { dengan Arca } \\
\text { Prajnaparamita/ } \\
\text { Arca Ken } \\
\text { Dedes. }\end{array}$} & \multirow[b]{2}{*}{$\begin{array}{l}\text { Tidak ada } \\
\text { konsep dalam } \\
\text { konteks Katolik. } \\
\text { Namun } \\
\text { menciptakan } \\
\text { pemahaman } \\
\text { karakteristik } \\
\text { Bunda Maria } \\
\text { yang serupa } \\
\text { dengan } \\
\text { Boddhisatva } \\
\text { Prajnaparamita. }\end{array}$} & $v$ & & $\mathbf{v}$ & \\
\hline & & & & \multicolumn{4}{|c|}{$\begin{array}{l}\text { Secara pemaknaan } \\
\text { maupun visual } \\
\text { lebih mengarah ke } \\
\text { gaya maupun } \\
\text { pemaknaan Hindu- } \\
\text { Jawa, namun } \\
\text { konsep ekspresi } \\
\text { meditatif Bunda } \\
\text { Maria juga telah } \\
\text { dipraktekkan dalam } \\
\text { kebudayaan Barat. }\end{array}$} \\
\hline & \multirow[b]{2}{*}{$\begin{array}{l}\text { Gestur yang } \\
\text { menggendong } \\
\text { anak kecil } \\
\text { dengan mahkota } \\
\text { kepala, tangan } \\
\text { kanan di dada, } \\
\text { wajah tegak ke } \\
\text { depan dan } \\
\text { ekspresi yang } \\
\text { sama dengan } \\
\text { sang Ibu. }\end{array}$} & \multirow[b]{2}{*}{$\begin{array}{l}\text { Tidak ada } \\
\text { konsep dalam } \\
\text { Hindu-Buddha. } \\
\text { Namun gestur } \\
\text { dan ornamen } \\
\text { yang dikenakan } \\
\text { anak tersebut } \\
\text { menunjukkan } \\
\text { sang Anak } \\
\text { adalah seorang } \\
\text { Pangeran. }\end{array}$} & \multirow[b]{2}{*}{$\begin{array}{l}\text { Memberikan } \\
\text { kejelasan bahwa } \\
\text { Arca tersebut } \\
\text { adalah Arca } \\
\text { Bunda Maria } \\
\text { dan Anak, } \\
\text { dikarenakan } \\
\text { sang Anak juga } \\
\text { mengunakan } \\
\text { mahkota kepala } \\
\text { yang } \\
\text { menunjukkan } \\
\text { statusnya. }\end{array}$} & $\boldsymbol{v}$ & & & \\
\hline 1 & & & & \multicolumn{4}{|c|}{$\begin{array}{l}\text { Meskipun } \\
\text { menggunakan gaya } \\
\text { Hindu-Jawa dalam } \\
\text { visualnya, namun } \\
\text { tidak ada referensi } \\
\text { gestur ini dalam } \\
\text { kebudayaan Hindu- } \\
\text { Jawa. Oleh karena } \\
\text { itu, bisa dianggap } \\
\text { bahwa } \\
\text { pemaknaannya } \\
\text { lebih mengarah ke } \\
\text { Katolik. }\end{array}$} \\
\hline
\end{tabular}


Vol. 2, No. 2, Desember 2017, pISSN 2527-2853, eISSN 2549-2985

\begin{tabular}{|c|c|c|c|c|c|c|c|}
\hline \multirow{3}{*}{ Visual } & \multirow{3}{*}{ Deskripsi } & \multirow{3}{*}{$\begin{array}{c}\text { Pemahaman } \\
\text { Hindu - } \\
\text { Buddha }\end{array}$} & \multirow{3}{*}{$\begin{array}{l}\text { Pemahaman } \\
\text { KaTOLIK }\end{array}$} & \multicolumn{4}{|c|}{ Analisis } \\
\hline & & & & \multicolumn{2}{|c|}{ Visual } & \multicolumn{2}{|c|}{ Makna } \\
\hline & & & & H/B & $\mathbf{K}$ & H/B & $\mathbf{K}$ \\
\hline & \multirow[b]{2}{*}{$\begin{array}{l}\text { Posisi tubuh } \\
\text { duduk. Motif } \\
\text { pakaian yang } \\
\text { dikenakan Ibu } \\
\text { nampak jelas, } \\
\text { yaitu } \\
\text { menggunakan } \\
\text { batik motif } \\
\text { parang rusak } \\
\text { diatas batik } \\
\text { motif kawung, } \\
\text { lengkap dengan } \\
\text { ornamen hiasan } \\
\text { kaki. }\end{array}$} & \multirow[b]{2}{*}{$\begin{array}{l}\text { Posisi duduk } \\
\text { adalah salah } \\
\text { satu posisi pada } \\
\text { arca Buddha. } \\
\text { Parang rusak: } \\
\text { Diciptakan } \\
\text { oleh } \\
\text { Panembahan } \\
\text { Senopati, } \\
\text { melambangkan } \\
\text { jiwa manusia } \\
\text { yg menang } \\
\text { melawan } \\
\text { kejahatan } \\
\text { dengan } \\
\text { mengendalikan } \\
\text { keinginan } \\
\text { dengan } \\
\text { bijaksana dan } \\
\text { kemuliaan } \\
\text { karakter. } \\
\text { Kawung: agar } \\
\text { manusia dapat } \\
\text { berguna bagi } \\
\text { siapa saja, dan } \\
\text { tidak pernah } \\
\text { melupakan } \\
\text { asal-usulnya. }\end{array}$} & \multirow[b]{2}{*}{$\begin{array}{l}\text { Pada umumnya, } \\
\text { patung Bunda } \\
\text { Maria selalu } \\
\text { digambarkan } \\
\text { dalam posisi } \\
\text { berdiri; namun } \\
\text { ada beberapa } \\
\text { yang duduk, } \\
\text { seperti pada } \\
\text { patung Pieta } \\
\text { karya } \\
\text { Michaelangelo. }\end{array}$} & 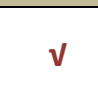 & & $\mathbf{v}$ & \\
\hline it & & & & \multicolumn{4}{|c|}{$\begin{array}{l}\text { Secara visual lebih } \\
\text { mengarah ke } \\
\text { Hindu-Jawa, } \\
\text { sedangkan } \\
\text { pemaknaan gestur } \\
\text { 'duduk' itu sendiri } \\
\text { lebih bersifat netral } \\
\text { pada Katolik. Di } \\
\text { kebudayaan Jawa } \\
\text { sendiri, gestur } \\
\text { 'duduk' } \\
\text { melambangkan } \\
\text { unsur kekuasaan } \\
\text { yang lebih tinggi, } \\
\text { sedangkan para } \\
\text { abdi digambarkan } \\
\text { dengan gestur } \\
\text { duduk simpuh } \\
\text { bersila (dibawah). }\end{array}$} \\
\hline & \multirow{2}{*}{$\begin{array}{l}\text { Landasan kaki } \\
\text { berbentuk } \\
\text { silinder dengan } \\
\text { hiasan kelopak } \\
\text { bunga padma, } \\
\text { dinamakan } \\
\text { dengan } \\
\text { padmasana. }\end{array}$} & \multirow{2}{*}{$\begin{array}{l}\text { Padmasana, } \\
\text { atau tempat } \\
\text { duduk bunga } \\
\text { lotus yang } \\
\text { melambangkan } \\
\text { kesucian lahir } \\
\text { batin. }\end{array}$} & \multirow[b]{2}{*}{$\begin{array}{l}\text { Tidak ada } \\
\text { konsep. Namun } \\
\text { Padmasana ini } \\
\text { dimaksudkan } \\
\text { sebagai } \\
\text { pengganti } \\
\text { lingkaran } \\
\text { kesucian/ halo } \\
\text { yang biasa } \\
\text { digunakan } \\
\text { sebagai } \\
\text { perlambang } \\
\text { orang-orang } \\
\text { suci. }\end{array}$} & v & & & $\mathbf{v}$ \\
\hline $\ln$ & & & & \multicolumn{4}{|c|}{$\begin{array}{l}\text { Secara visual } \\
\text { maupun makna, } \\
\text { melambangkan } \\
\text { konsepsi 'kesucian' } \\
\text { dalam kebudayaan } \\
\text { Hindu/ Buddha. }\end{array}$} \\
\hline
\end{tabular}


Ira Audia Agustina, Andryanto Wibisono, Imam Santosa

Analisa Sinkretisme Agama dan Budaya Melalui Transformasi Elemen Visual Bernilai Sakral pada Gereja

Katolik Ganjuran

\begin{tabular}{|c|c|c|c|c|c|c|c|}
\hline \multirow{3}{*}{ Visual } & \multirow{3}{*}{ Deskripsi } & \multirow{3}{*}{$\begin{array}{c}\text { Pemahaman } \\
\text { Hindu - } \\
\text { Buddha }\end{array}$} & \multirow{3}{*}{$\begin{array}{c}\text { Pemahaman } \\
\text { KaTOLIK }\end{array}$} & \multicolumn{4}{|c|}{ Analisis } \\
\hline & & & & \multicolumn{2}{|c|}{ Visual } & \multicolumn{2}{|c|}{ Makna } \\
\hline & & & & H/B & $\mathbf{K}$ & H/B & $\mathbf{K}$ \\
\hline & $\begin{array}{l}\text { Gelar } \\
\text { kebangsawanan }\end{array}$ & $\begin{array}{l}\text { Tidak ada } \\
\text { konsep. }\end{array}$ & $\begin{array}{l}\text { Melalui Gelar } \\
\text { tersebut }\end{array}$ & V & & & $\checkmark$ \\
\hline 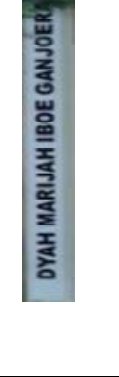 & $\begin{array}{l}\text { Jawa yang } \\
\text { disematkan pada } \\
\text { Arca Bunda } \\
\text { Maria. }\end{array}$ & & $\begin{array}{l}\text { diketahui bahwa } \\
\text { Bunda Maria } \\
\text { dalam sudut } \\
\text { pandang Jawa } \\
\text { mempunyai } \\
\text { status sebagai } \\
\text { Ratu (Ibu sang } \\
\text { Raja). }\end{array}$ & \multicolumn{4}{|c|}{$\begin{array}{l}\text { Secara pemaknaan } \\
\text { mengkonotasikan } \\
\text { dengan jelas pada } \\
\text { konsep Katolik. }\end{array}$} \\
\hline
\end{tabular}

Pada analisa unsur-unsur visual pada Arca Bunda Maria, diketahui bahwa meskipun menggunakan visualisasi konsep Hindu-Buddha, namun penafsiran secara Katolik dapat tercipta melalui unsur-unsur visual berikut ini:

1. Gestur tokoh pada Arca yang sedang menggendong anak kecil yang berpakaian kebesaran lengkap pada pangkuannya.

2. Penyematan tanda/simbol berupa tulisan gelar yang terdapat dibawah Arca.

Melalui penggambaran Bunda Maria dengan menggunakan model Buddhist Prajnaparamita, memberikan penafsiran terhadap sosok dan karakteristik Bunda Maria yang telah mencapai kesempurnaan dalam kebijaksanaan transedental. Sebagai seorang yang telah mencapai tngkatan kebijaksanaan transedental yang sempurna, maka raut wajahnya memancarkan keteduhan, kedamaian dan ketenangan. Landasan padmasana dibawah kakinya menunjukkan kesucian yang dimilikinya. Gelar yang disematkan yaitu "Dyah Marijah Iboe Gandjoeran" mempertegas sosok Arca tersebut sebagai sosok seorang ibu dari seorang Pangeran/calon Raja.

\section{KESIMPULAN}

Sinkretisme agama terhadap kebudayaan lokal Jawa melalui elemen-elemen visualnya memang terbukti efektif dalam menciptakan penerimaan masyarakat terhadap nilai-nilai baru yang datang. Sinkretisme adalah suatu gejala umum dan telah menjadi bagian dari kepribadian masyarakat Jawa itu sendiri. Hal ini terbukti melalui tidak adanya penolakan masyarakat terhadap penggunaan unsur - unsur visual yang bernilai sakral dalam Hindu-Jawa tersebut untuk kemudian disematkan nilai-nilai Kekristenan didalamnya. Proses sinkretisme dalam elemen visual bernilai sakral Gereja Ganjuran itu sendiri terjadi melalui tahapan analogis, yaitu suatu proses kognitif otak saat mentransfer informasi atau makna dari suatu subyek tertentu (dalam hal ini unsur visual Hindu-Jawa) kepada subyek lainnya (nilai Kekristenan). Tahapan analogis dalam sinkretisme ini tidak menghilangkan salah satu dari kedua unsur makna tersebut, melainkan menggabungkan keduanya menjadi satu kesatuan yang khas yang unik mengenai Kekatolikan dalam cara pandang Hindu-Jawa.

Pemaknaan analogis pada elemen visual bernilai sakral Gereja Ganjuran ini secara kognitif tidak menghilangkan aspek mitologis agama Hindu-Jawa dalam prosesnya, melainkan mentransfernya kedalam nilai Kekatolikan, sehingga yang terjadi adalah sebuah nilai kesakralan Katolik yang bermuatan mitologis Hindu-Jawa didalam unsur-unsur visualnya. Bedasarkan proses inilah, maka elemen-elemen visual bernilai sakral pada Gereja Ganjuran 
Vol. 2, No. 2, Desember 2017, pISSN 2527-2853, eISSN 2549-2985

dapat diterima dengan baik oleh masyarakat maupun umat Katolik-Jawa itu sendiri, dan dapat mampu membuka pemahaman yang lebih mendalam mengenai ajaran Kekatolikan dalam sudut pandang seorang manusia Jawa seutuhnya.

\section{DAFTAR PUSTAKA}

Conway, H., \& Roenisch, R. (2005). Understanding Architecture. New York: Routledge.

Dillistone, F. W. (2002). The Power of Symbols. Yogyakarta: Kanisius.

Geertz, C. (2013). Agama Jawa : Abangan, Santri, Priyayi dalam kebudayaan Jawa. Depok: Komunitas Bambu.

Hashemnezhad, H., Heidari, a. A., \& Hoseini, P. M. (Vol. 3, No. 1. 2013). Sense of Place and Place Attachment. International Journal of Architecture and urban Development , 3-12.

Hernandez, B., Hidalgo, M. C., \& M. Esther Salazar-Laplace, S. H. (2007). Place Attachment and Place Identity in Natives \& Non Natives. Journal of Environmental Psychology, 310-319.

Hidajat, R. (2006). Relasional Simbolis Desa, Sungai dan Pundhen dengan pertunjukan wayang topeng malang di dusun kedungmonggo, karangpandan. Kejawen, Jurnal Kebudayaan Jawa, 14-37.

Hidalgo, M. C., \& Hernandez, B. (2001). Place Attachment : conceptual and Empirical Question. Journal of Environmental Psychology, 273-281.

KWI, K. T. (2012). Kompendium Konsili Vatikan II. Yogyakarta: Kanisius.

Laksana, A. B. (2011). Journeying to God in Communion With The Other: A Comparative Theological Study of The Muslim and Catholic Pilgrimage Traditions in South Central Java and Their Contributions To The Catholic Theology of Communio Sanctorum. United States: UMI Dissertation Publishing.

Magnis-Suseno, F. (2003). Etika Jawa. Jakarta: PT. Gramedia Pustaka Utama.

Mangunwijaya, Y. B. (1988). Wastu Citra. Yogyakarta: PT. Gramedia.

Mazumdar, S., \& Mazumdar, S. (2004). Religion and Palce Attachment : A Study of Sacred Places. Journal of Environmental Psychology, 385-397.

Pennick, N. (1980). Sacred Geometry. Northamptonshire: Weatherby Woolnough.

Sheldrake, P. (2001). Spaces for the Sacred : Place, Memory, and Identity. Baltimore, Maryland: John Hopkins University Press.

Simmins, G. (2008). Sacred Spaces and Sacred Places. VDM Verlag.

Srisadono, Y. D. (2012). Konsep Sacred Space dalam Arsitektur Gereja Katolik. Melintas , 182-206.

Suryanugraha, C. H. (2006). Rupa dan Citra: Aneka Simbol dalam Misa. Bandung: SangKris.

Tedjoworo, H. (2012). Re-interpreting the Catholic's Images of the Church in Java Part II. Melintas , 139-160.

Utomo, R. G. (2011). Gereja Hati Kudus Yesus di Ganjuran. Yogyakarta: Unggul Jaya.

Waxman, L. (2006). The Coffee Shop : Social and Physical Factors Influencing Place Attachment. Journal of Interior Design , 35-53.

Widagdo. (2011). Desain \& Kebudayaan. Bandung: Penerbit ITB.

Williams, D. R., Patterson, M. E., \& Rogenbuck, J. W. (1992). Beyond The Commodity Metaphor : Examining emotional and Symbolik Attachment to Place. Leisure Science , 29-46. 
Ira Audia Agustina, Andryanto Wibisono, Imam Santosa

Analisa Sinkretisme Agama dan Budaya Melalui Transformasi Elemen Visual Bernilai Sakral pada Gereja

Katolik Ganjuran 